\title{
PILOT APPLICATION OF 3D UNDERWATER IMAGING TECHNIQUES FOR MAPPING POSIDONIA OCEANICA (L.) DELILE MEADOWS
}

\author{
F.S. Rende ${ }^{a *}$, A.D. Irving ${ }^{b}$, A. Lagudi $;$ F. Bruno ${ }^{\text {c }}$, S. Scalise ${ }^{\text {d }}$ P. Cappa ${ }^{\text {d }}$; M. Montefalcone ${ }^{\mathrm{e}}$, T. Bacci ${ }^{\mathrm{a}}$; M. Penna ${ }^{\mathrm{a}}$; B. Trabucco ${ }^{\mathrm{a}}$; \\ R. Di Mento ; A.M. Cicero ${ }^{\mathrm{a}}$

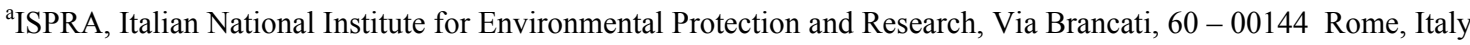 \\ rende.francesco@isprambiente.it \\ ${ }^{\mathrm{b}}$ School of Medical and Applied Sciences, Central Queensland University, Rockhampton, Queensland 4702, Australia" \\ ${ }^{c}$ DIMEG - Dipartimento di Ingegneria Meccanica, Energetica e Gestionale, Università della Calabria, Arcavacata di Rende, Italy. \\ ${ }^{\mathrm{d}}$ Marine Protected Area of Capo Rizzuto, Via Cristoforo Colombo s.n.c. - 88900, Crotone, Italy \\ ${ }^{\mathrm{e}}$ Distav, University of Genoa, corso Europa, 26 - 16132 Genoa, Italy
}

\section{Commission V}

KEY WORDS: Posidonia oceanica, optical instruments, 3D mapping, 3D reconstruction, quality status

\begin{abstract}
:
Seagrass communities are considered one of the most productive and complex marine ecosystems. Seagrasses belong to a small group of 66 species that can form extensive meadows in all coastal areas of our planet. Posidonia oceanica beds are the most characteristic ecosystem of the Mediterranean Sea, and should be constantly monitored, preserved and maintained, as specified by EU Habitats Directive for priority habitats. Underwater 3D imaging by means of still or video cameras can allow a detailed analysis of the temporal evolution of these meadows, but also of the seafloor morphology and integrity. Video-photographic devices and open source software for acquiring and managing 3D optical data rapidly became more and more effective and economically viable, making underwater 3D mapping an easier task to carry out. 3D reconstruction of the underwater scene can be obtained with photogrammetric techniques that require just one or more digital cameras, also in stereo configuration. In this work we present the preliminary results of a pilot 3D mapping project applied to the P. oceanica meadow in the Marine Protected Area of Capo Rizzuto (KR, Calabria Region- Italy).
\end{abstract}

\section{INTRODUCTION}

Seagrass communities are considered one of the most productive and complex marine ecosystems. Seagrasses belong to a small group of 66 species that can form extensive meadows in all coastal areas of our planet., (Ruìz et al., 2009).

Posidonia oceanica beds are the most characteristic ecosystem of the Mediterranean Sea, and probably the most important. $P$. oceanica meadows have three - dimensional structure, and form terraces, channels and barrier reefs that can reach a height of 3-4 m, (Culbertson, 2009).

$P$. oceanica forms extensive meadows on soft and hard substrata, from sea surface till $25-40 \mathrm{~m}$ depth, (Boudouresque et al., 2009). P. oceanica meadows have been defined as priority habitats and should be constantly monitored, preserved and maintained, as specified by EU Habitats Directive for priority habitats, (Gibson et al., 2007).

Surveying methods for seagrasses and benthic communities can be carried out directly (i.e. by a scientific diver or a technical operator) or, alternatively, indirectly by means of optical, electro-acoustical instruments, etc. (Eleftheriou, 2013). Underwater video and photography, used together with image analysis software, can be effective methods to determine the coverage and the structural characteristics of submerged vegetation and bottom sediments (Norris et al., 1997; McDonald et al., 2006; Schultz et al., 2014)

Moreover, underwater imaging is an important tool to understand geological and biological processes taking place on the seafloor, providing scientists with high levels of detail and the ease of interpretation. Underwater 3D mapping has normally been carried out by acoustic multibeam sensors or side scan sonar (Paul et al., 2011; Micallef et al., 2012; Montefalcone et al., 2013; Campos et al., 2014). However, the information provided by acoustic devices is normally gathered in the form of elevation maps, which are useful for providing a rough approximation of the global shape of the area, but are inadequate for detecting more complex structures, (Campos et al., 2014).

Underwater 3D imaging by means of still or video cameras can allow a detailed analysis of the temporal evolution of these meadows, but also of the seafloor morphology and integrity, (Mallet et al., 2014). This method was - still up to a few years ago - time consuming and very expensive, but in the last decade 3D imaging technologies have known substantial technical advancements, with lower costs too.

Video-photographic devices and open source software for acquiring and managing $3 \mathrm{D}$ optical data rapidly became more and more effective and economically viable, making underwater 3D mapping an easier task to carried out. 3D reconstruction of the underwater scene can be obtained though the use of photogrammetric techniques that require just one or more digital cameras, also in stereo configuration, (Cocito et al., 2003, Pizzarro et al., 2004).

Three-dimensional structures, i.e. complex topographic structures are strongly related with marine biodiversity since they affect community structure and consequently, ecological

* Corresponding author 
processes. In Ecology habitat complexity is usually described with quantitative and qualitative indexes such as rugosity, slope and aspect (Friedman et al., 2012; Zapata-Ramírez et al., 2013) Three-dimensional underwater photography allows theanalysis of marine ecosystems evolution and the representation of seafloor morphology. In order to obtain 3D information, scene key points from multiple underwater views (either supplied by multiple cameras or by a single moving camera) can be used to extract 3D estimates (Hurtós et al., 2009). For this work were considered the most representative images of the structural and morphological aspects of the $P$. oceanica meadow.

\section{METHODOLOGY}

\subsection{Study area}

Field activities were carried out in July 2014 at the Marine Protected Area of Capo Rizzuto (KR, Calabria Region - Italy). The image acquisitions were performed at nine sites (Fig.1), at a sea depth ranging from 1 to 10 meters. Each transect was performed on an average length of about $1 \mathrm{Km}$. Photo transects were taken following paths parallel to the coastline and maintaining a the same distance from the bottom (Fig.2).

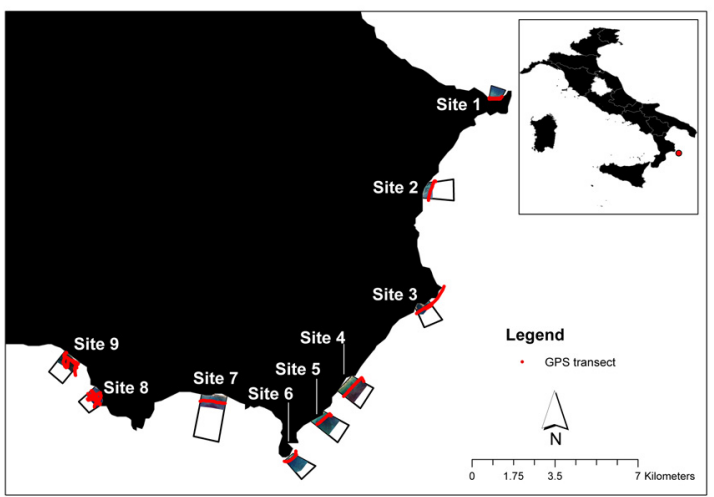

Figure 1. Geographical localization of the investigated sites at the Marine Protected Area of Capo Rizzuto (KR).

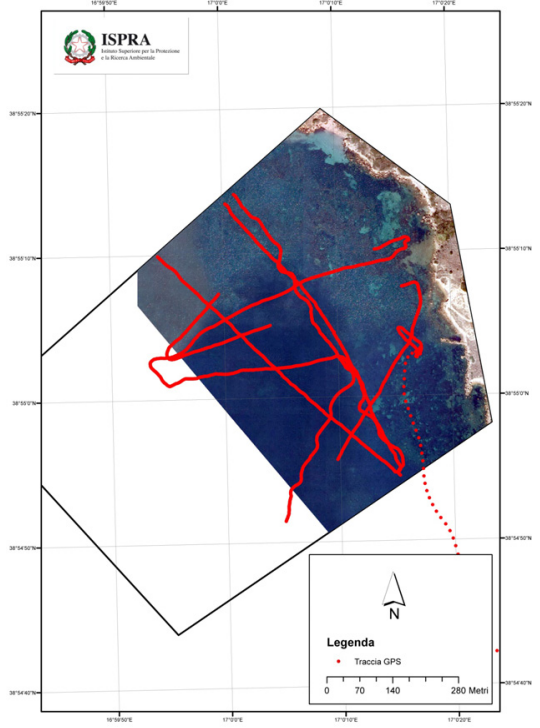

Figure 2. Example of the investigated area: site n.8 at the Marine Protected Area of Capo Rizzuto (KR).

\subsection{Experimental setup and image acquisition}

We used Towed Video Camera Systems (Fig.3), equipped with a GoPro Hero $3^{+}$Black model, which is a consumer-brand highdefinition sport camera with a 12MP HD CMOS sensor, 1/2.5" in size. It uses a fixed-focus lens, which is made with professional-grade glass and has a maximum aperture of $\mathrm{f} / 2.8$. The GOPRO Hero $3^{+}$records at different video and photo resolutions and Field-Of-View (FOV). In this work we have used the GOPRO camera (set in time lapse mode) with 12MP widescreen $1080 \mathrm{p}$ and a FOV of $108^{\circ}$. The camera was positioned in "face down". This allowed us to obtain vertical images at the same distance from the sea bottom. Georeferenced images have been obtained by coupling a GPS data logger model Blumax 4404. In order to acquire overlapping pictures, ensuring about a $75 \%$ of shared coverage between two consecutive photos, it was kept a diving speed of 1 knot/hour. About 1000 images for each transect have been gathered.

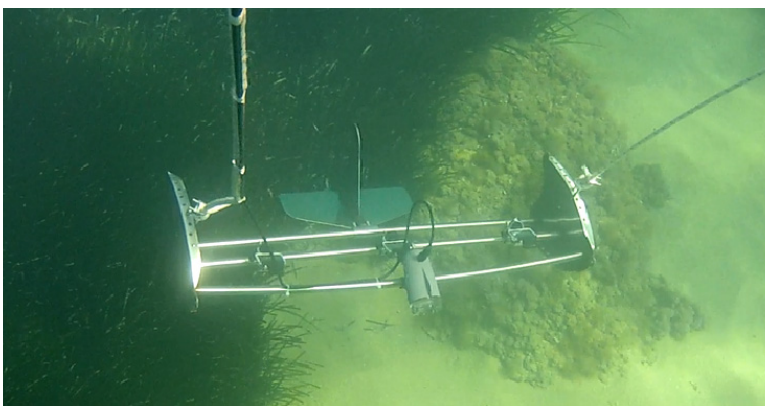

Figure 3. Underwater Towed Sled Systems developed within Svi.Str.In. (C) Project

\subsection{Image enhancement}

Before 3D processing, the underwater images datasets have been elaborated with image enhancement techniques in order to reduce blur due to scattering effects and correct color casts (remove greenish-blue components). As first step, sharp filtering has been performed to remove the fog in the images, due to the scattering effects, which decreased image contrast and increased the blur. Secondly, the images are color corrected by using a new method (Bianco, 2015) based on white balancing in the $1 \alpha \beta$ color space. This method allows to remove the color casts in underwater images that are tipically affected by color alterations, by balancing the chromatic components $(\alpha$ and $\beta$ ), while luminance component (l) is used to improve image contrast by cutoff and histogram stretching (Fig. 4).

The method is particularly suitable to process our datasets because it has been proposed for applications like close-range acquisition in downward direction, i.e. seafloor mapping. Fig.5 shows the final results after image enhancement processing.

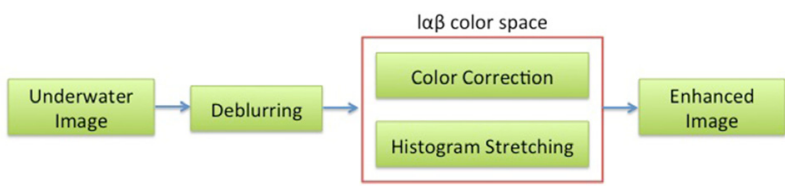

Figure 4. Flow-chart of the image enhancement steps. 


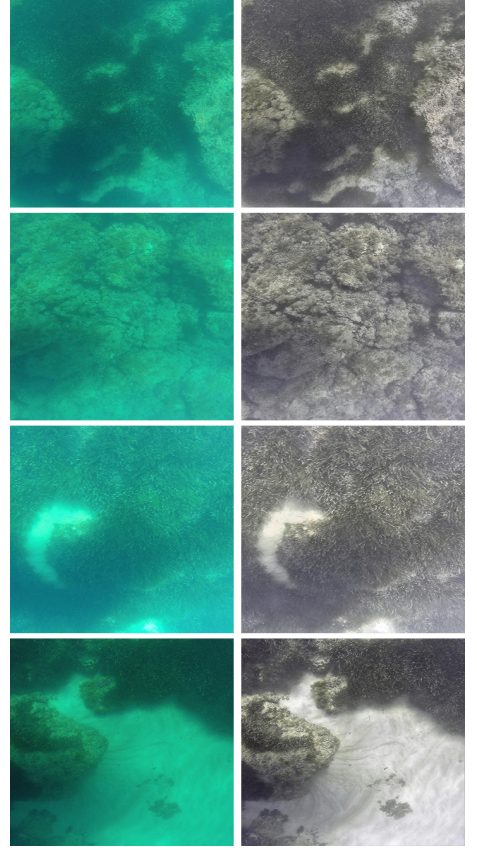

Figure 5. Some results of the image enhancement processing.

\subsection{D reconstruction}

After the image enhancement step, dataset have been processed through a multi-view dense stereo algorithm to obtain 3D models of the meadow. These preliminary results allowed us to evaluate the structural and morphological aspects of the $P$. oceanica meadow and to determine its conservation status. Considering the site 8 as reference, the $3 \mathrm{D}$ reconstruction pipeline starts from the orientation of all the 1000 pictures by using open source software for multi-view 3D reconstruction. We used Bundler software (Snavely et al., 2007) to orient the images and to retrieve the camera calibration parameters. The first phase uses the SIFT (Scale Invariant Feature Transform) to extract a set of descriptors across the collection of images that are subsequently matched. The output of Bundler consists in the intrinsic and extrinsic parameters for each camera pose and in a sparse reconstruction of the scene. The $3 \mathrm{D}$ reconstruction has been conducted on both original and enhanced dataset. We find that the image enhancement step improves considerably the matching results. In fact, the full set of original incorrect images has not been successfully oriented, and it has been necessary to divide the dataset into two groups and to reconstruct them separately. This is mainly caused by the sandy seabed present in the central part of the transect, which makes the extraction and matching of features difficult, due to the low contrast. On the contrary, the use of enhanced images allowed to orient a subset of 800 pictures related to the whole area, generating a complete 3D point cloud without the need of align different meshes. Subsequently, the Bundler's outputs and the undistorted images have been processed with PMVS2 (Patch-based Multi-View Stereo) algorithm (Furukawa et al., 2010). This algorithm estimates the surface orientation while enforcing the local photometric consistency, which is important to obtain accurate models for low textured objects or with images affected by blur due to turbidity in underwater environment. Furthermore PMVS2 automatically reject moving objects, such as fishes and algae. The output is a dense point cloud (about 1 million points) with RGB information for each 3D point (Fig. 6).
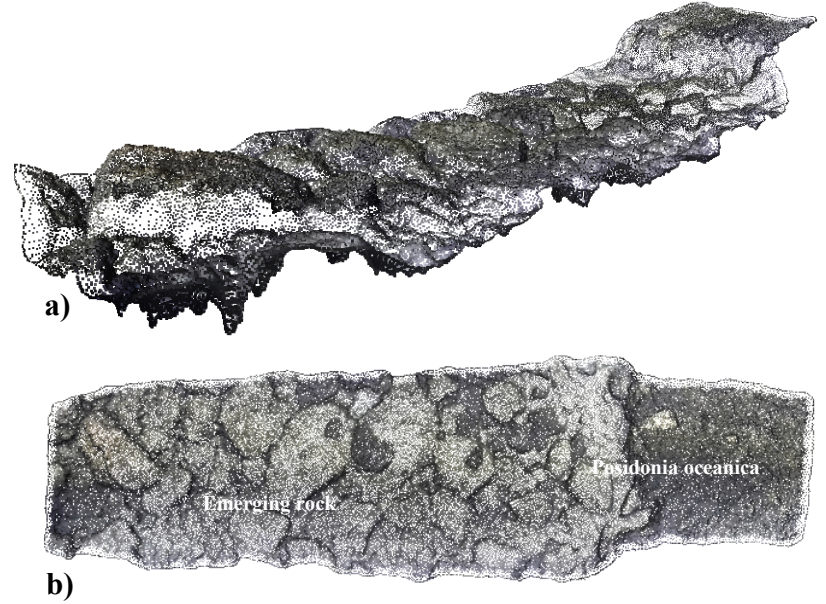

Figure 6. Prospect view reconstructed dense point cloud of a portion of the transect (site 8); b) orthogonal view dense point cloud.

The point cloud has been processed with the open source software Meshlab (Meshlab, 2015). The first operation was a manual selection and deletion of unwanted areas. Then, a watertight surface with about 2.5 million triangles has been obtained through a Poisson Surface Reconstruction algorithm. The resulting surface has been subsequently decimated in a mesh of 800.000 triangles in order to be handled efficiently by an interactive visualization software (Fig. 7)
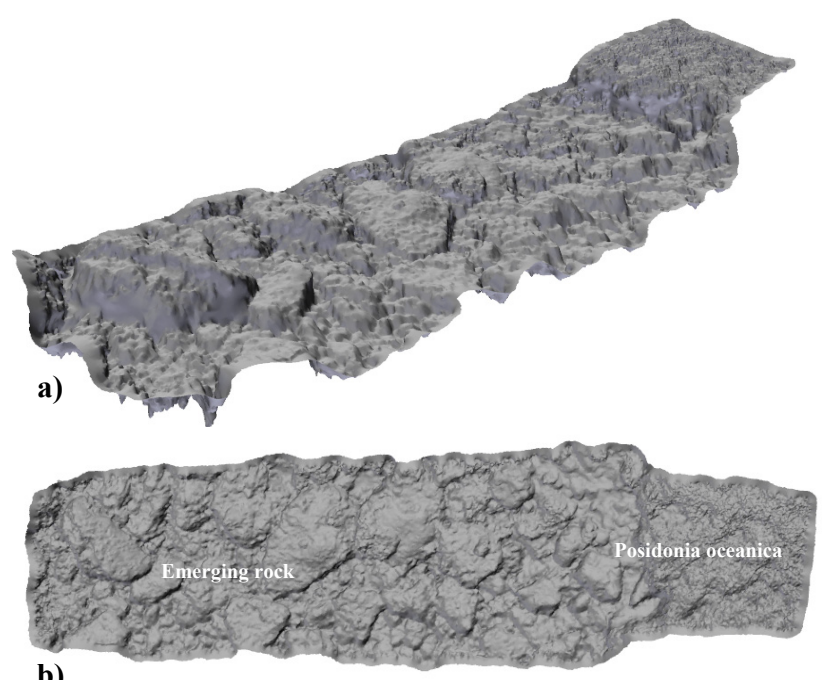

b)

Figure 7. a) Prospect view resulting 3D surface of the portion of the transect (site 8); b) orthogonal view 3D surface. .

The last step consists in the application of the texture on the 3D surface. Color information can be extracted directly from the colored point cloud, but this method does not allow the creation of an high quality texture, because its resolution depends on the point cloud density. Since the camera positions are known, the method chosen for texture mapping consists into the projection and blending of the high resolution images directly on the 3D surface. In particular, we have selected an image subset because the averaging among neighbourhood values during the blending on the images works better if performed on a largely overlapped area (reducing blur effects). The result of this procedure is a texture with a resolution comparable to the original images (Fig. 8) 

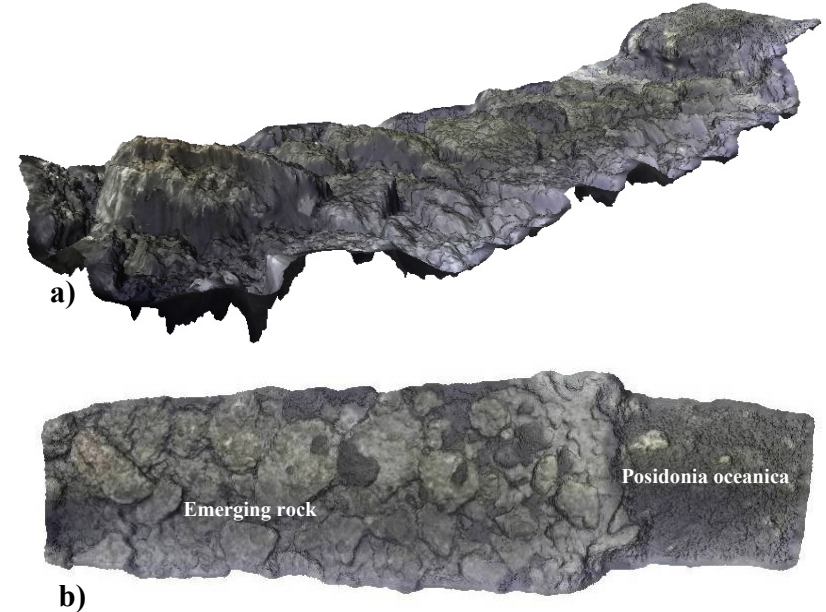

Figure 8. a) Prospect view final textured 3D model of the selected area of the transect (site 8 ); b) orthogonal view 3D model.

\section{3D MODEL ANALYSIS}

From the 3D reconstruction, performed on most images of the investigated sites, we could appreciate the potential applications of this 3D imaging technique, both in terms of accurate morphological details characterizing parts of mapped meadows, and potential information obtainable from a 3D model. Fig. 9 shows $3 \mathrm{D}$ reconstructions of six different morphological and geomorphological characters.
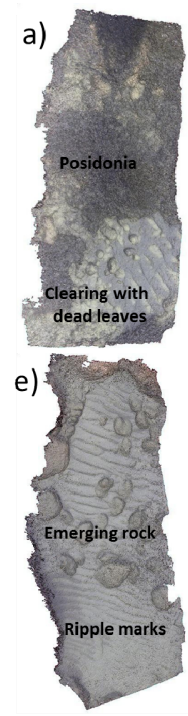

b)

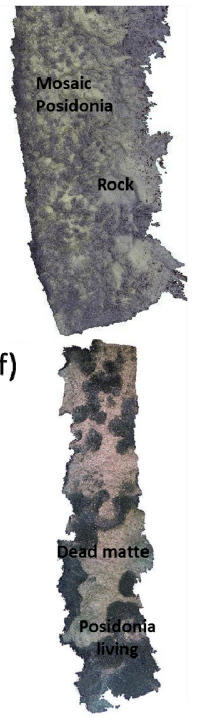

c)

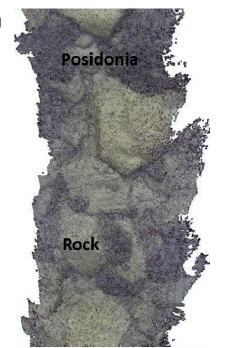

g)

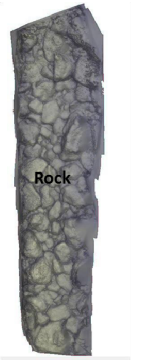

Figure 9. Orthogonal view 3D models of the structural and morphological aspects of the P. oceanica meadow of MPA Capo Rizzuto.

Specifically, in Fig.9a to, meadow is implanted on bedrock, with adjacent large cleared area with dead leaves deposition. In Fig.9b is shown the typical morphological character of meadows on bedrock, having low coverage and high fragmentation, (detail is represented in Fig.9c.) Fig.9e shows a sandy bottom that is affected by wave action, as evidenced by the presence of ripple marks. In Fig.9f meadow is established on matte boundary with the presence of dead matte. Finally,
Fig. $8 \mathrm{~g}$ shows the $3 \mathrm{D}$ reconstruction of a rocky bottom made up of large boulders.

\section{CONCLUSIONS}

In this work, we've presented a preliminary results concerning the application of the 3D imaging techniques for reconstruction of underwater scenes that show structural and morphological characteristics of $P$. oceanica meadow. Through the presented results, we've verified that the presented image-based reconstruction techniques are applicable in acquatic environments. These results confirm that the methodology and approach are applicable for generating 3D reconstructions of seabed morphological structures. This method has broad applications for studying the quality status of the seagrass meadows and for assessing long-term and spatial variability.

\section{ACKNOWLEDGEMENTS}

We would like to thank Mr. Gianfranco Bianco (University of Calabria - Italy) in collaboration with Dr. L. Neumann (ICREA, Barcelona - Spain) and Dr. R. Garcia (Universitad de Girona Spain) for the image enhancement elaborations. This study has been performed within the project Svi.Str.In "Sviluppo Strumenti Innovativi" financed by the MPA of Capo Rizzuto in 2014.

\section{REFERENCES}

Bianco, G., Neumann, L., Garcia, R., Muzzupappa, M., Bruno, L., 2015. A new color correction method for underwater imaging, ISPRS/CIPA workshop "UNDERWATER 3D RECORDING AND MODELING". Piano di Sorrento (NaplesItaly). 16-17 April 2015.

Boudouresque, C. F., Bernard, G., Pergent, G., Shili, A., \& Verlaque, M., 2009. Regression of Mediterranean seagrasses caused by natural processes and anthropogenic disturbances and stress: a critical review. Botanica Marina, 52(5), 395-418.

Campos, R., Garcia, R., Alliez, P., \& Yvinec, M. (2014). A surface reconstruction method for in-detail underwater 3D optical mapping. The International Journal of Robotics Research, 0278364914544531.

Cocito, S., Sgorbini, S., Peirano, A., \& Valle, M., 2003. 3-D reconstruction of biological objects using underwater video technique and image processing. Journal of experimental marine biology and ecology, 297(1), 57-70.

Culbertson, J., 2009.Global loss of coastal habitats: Rates, causes and consequences. C. M. Duarte, \& B. B. V. A. Fundación (Eds.). Madrid, Spain: Fundación BBVA.

Eleftheriou, A., (Ed.). 2013. Methods for the study of marine benthos. John Wiley \& Sons.

Friedman, A., Pizarro, O., Williams, S. B., \& JohnsonRoberson, M., 2012. Multi-scale measures of rugosity, slope and aspect from benthic stereo image reconstructions. PloS one, 7 (12), e50440.

Furukawa, Y., \& Ponce, J., 2010. Accurate, dense, and robust multiview stereopsis. Pattern Analysis and Machine Intelligence, IEEE Transactions on, 32(8), 1362-1376. 
Gibson, R. N., Atkinson, R. J. A., \& Gordon, J. D. M., 2007. Loss, status and trends for coastal marine habitats of Europe. Oceanography and Marine Biology: an annual review, 45, 345405.

Hurtós, M., i Soler, X. C., \& Salvi, J., 2009. Integration of optical and acoustic sensors for D underwater scene reconstruction. Instrumentation viewpoint, (8), 43.

Mallet, D., \& Pelletier, D., 2014. Underwater video techniques for observing coastal marine biodiversity: A review of sixty years of publications (1952-2012). Fisheries Research, 154, 44-62.

McDonald, J. I., Coupland, G. T., \& Kendrick, G. A., 2006. Underwater video as a monitoring tool to detect change in seagrass cover. Journal of environmental management, 80 (2), 148-155.

MESHLAB:, accessed on February 2015. URL: http://meshlab.sourceforge.net/. 5

Micallef, A., Le Bas, T. P., Huvenne, V. A., Blondel, P., Hühnerbach, V., \& Deidun, A., 2012. A multi-method approach for benthic habitat mapping of shallow coastal areas with highresolution multibeam data. Continental Shelf Research, 39, 1426.

Norris, J. G., Wyllie-Echeverria, S., Mumford, T., Bailey, A., \& Turner, T., 1997. Estimating basal area coverage of subtidal seagrass beds using underwater videography. Aquatic Botany, 58(3), 269-287.

Paul, M., Lefebvre, A., Manca, E., \& Amos, C. L., 2011. An acoustic method for the remote measurement of seagrass metrics. Estuarine, Coastal and Shelf Science, 93(1), 68-79.

Pizarro, O., Eustice, R., \& Singh, H., 2004. Large area 3D reconstructions from underwater surveys. In OCEANS'04. MTTS/IEEE TECHNO-OCEAN'04 (Vol. 2, pp. 678-687). IEEE.

Puhr, K., Schultz, S., Pikelj, K., Petricioli, D., \& BakranPetricioli, T., 2014. The performance, application and integration of various seabed classification systems suitable for mapping Posidonia oceanica (L.) Delile meadows. Science of The Total Environment, 470, 364-378.

Ruíz, J. M., Boudouresque, C. F., \& Enríquez, S. (2009). Mediterranean seagrasses. Botanica Marina, 52(5), 369-381.

Schulein, R., \& Javidi, B., 2008. Underwater multi-view threedimensional imaging. Display Technology, Journal of, 4(4), 351-353.

Schultz, S. T., Bakran-Petricioli, T., Kruschel, C., \& Petricioli, D., 2014. Monitoring of Posidonia meadows under the EC Habitats Directive: vehicular videography can estimate trends in coverage at low cost and high precision. In 5th Mediterranean Symposium on Marine Vegetation.

Snavely, N., Seitz, S. M., \& Szeliski, R., 2008. Modeling the world from internet photo collections. International Journal of Computer Vision, 80(2), 189-210.

Zapata-Ramírez, P. A., Scaradozzi, D., Sorbi, L., Palma, M., Pantaleo, U., Ponti, M., \& Cerrano, C., 2013. Innovative study methods for the Mediterranean coralligenous habitats. Advances in Oceanography and Limnology, 4(2), 102-119. 